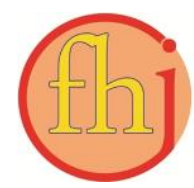

Faletehan Health Journal, 8 (2) (2021) 140-146

www. journal.Ippm-stikesfa.ac.id/ojs/index.php/FHJ

ISSN 2088-673X | e-ISSN 2597-8667

\title{
Pengaruh Pendidikan Kesehatan Asupan Cairan terhadap Kepatuhan Pembatasan Cairan Pasien Hemodialisis
}

\author{
Riswahyuni Widhawati ${ }^{1 *}$, Fitriani $^{1}$ \\ ${ }^{1}$ Prodi S1 Keperawatan, Sekolah Tinggi IImu Kesehatan IMC Bintaro, Tangerang Selatan, Banten \\ *Corresponding Author: riswidhawati@gmail.com
}

\begin{abstract}
Abstrak
Pasien Chronic Kidney Disease (CKD) yang rutin menjalani hemodialisis dua hingga tiga kali seminggu cenderung mengalami kelebihan volume cairan karena penurunan fungsi ginjal. Asupan volume cairan yang berlebih merupakan salah satu penyebab kematian pada pasien CKD. Tujuan penelitian ini adalah untuk mengetahui adanya pengaruh pendidikan kesehatan terhadap kepatuhan pembatasan asupan cairan pasien hemodialisis di Rumah Sakit Ichsan Medical Centre (IMC) Bintaro Tangerang Selatan. Penelitian ini menggunakan pendekatan kuantitatif dengan menggunakan metode quasi eksperimen dengan pendekatan pretest and post test non-equivalent control group design. Sampel penelitian berjumlah 40 pasien hemodialisis (20 pasien eksperimen dan 20 pasien kontrol). Intervensi pada kelompok eksperimen berupa pendidikan kesehatan tentang pembatasan asupan cairan. Pengumpulan data menggunakan kuisioner. Analisis yang digunakan adalah analisis univariat dan bivariat dengan uji paired sample $T$ test dan independent $T$ test. Hasil analisis data menunjukkan ada pengaruh pemberian pendidikan kesehatan pada kelompok eksperimen $(p=0,000)$, tetapi tidak ada perbedaan kepatuhan pembatasan cairan $(p=0,330)$ pada kelompok kontrol yang tidak diberikan pendidikan kesehatan. Peneliti menyimpulkan bahwa ada pengaruh pemberian pendidikan kesehatan terhadap tingkat kepatuhan pembatasan cairan pada pasien CKD.

Kata Kunci: Hemodialisis, Kepatuhan, Pendidikan Kesehatan, Pembatasan Cairan
\end{abstract}

\section{The Influence of Fluid Intake Health Education on Adherence to Fluid Restriction among Hemodialysis Patients}

\begin{abstract}
Patients with Chronic Kidney Disease (CKD) undergoing a regular hemodialysis twice a week or three times a week tend to experience an excessive fluid volume due to the decreased kidney function. An excessive fluid intake is one of causes of death in CKD patients. The study aims to examine the influence of health education on the adherence to fluid intake restriction among hemodialysis patients at Ichsan Medical Centre (IMC) Hospital in Bintaro, South Tangerang. This research used quantitative approach with quasi-experimental method and pretest and posttest non-equivalent control group design. The research sample consisted of 40 hemodialysis patients (20 experimental patients and 20 control patients). The intervention got by the experimental group was health education of fluid intake restriction. The data collection used questionnaire. The analysis used univariate and bivariate with paired sample $T$ test and independent $T$ test. The results of data analysis showed that there was influence of providing health education on the experimental group $(p=0.000)$, yet there was no difference of adherence to fluid restriction $(p=0.330)$ in the control group who got no health education. The researchers concluded that there is an influence of health education provision on the level of adherence to fluid restriction in CKD patients.
\end{abstract}

Keywords: Hemodialysis, Adherence, Health Education, Fluid Restriction 
Faletehan Health Journal, 8 (2) (2021) 140-146

www. journal.Ippm-stikesfa.ac.id/ojs/index.php/FHJ

ISSN 2088-673X | 2597-8667

\section{Pendahuluan}

Ginjal memiliki fungsi untuk mengeluarkan bahan dan sisa-sisa metabolisme yang tidak diperlukan oleh tubuh lagi, ginjal membuang zatzat yang tidak diperlukan lagi dan mengambil zatzat yang masih diperlukan tubuh, ginjal juga bertugas mengatur kadar air dan bahan lainnya di dalam tubuh (Corwin, 2009).

Pada pasien gagal ginjal kronik mempunyai karakteristik bersifat menetap, tidak bisa disembuhkan dan memerlukan pengobatan berupa hemodialisis, dialisis peritoneal, transplantasi ginjal dan rawat jalan dalam jangka waktu yang lama (Black \& Hawks, 2014). Menurut World Health Organization (WHO), data hingga 2015 diperkirakan tingkat presentase dari 2009 sampai 2011 ada sebanyak 36 juta warga dunia meninggal akibat Cronic Kidneys Diseases (CKD). Lebih dari 26 juta orang dewasa di Amerika atau sekitar $17 \%$ dari populasi orang dewasa terkena CKD atau gagal ginjal kronik (Bomback \& Bakris, 2011).

Data dari Indonesia Renal Registry (IRR) terdapat jumlah pasien baru dan pasien aktif yang menjalani hemoialisis di Indonesia mencapai 108.273 orang pada tahun 2017, terjadi peningkatan 38,5 \% dari tahun 2016 ("IRR (Indonesian Renal Registry)," 2017). Dalam survey pendahuluan, didapatkan dosis dialisis yaitu 10 - 15 jam per minggunya. Keberhasilan pengobatan pada pasien CKD dipengaruhi oleh banyak hal. Diantaranya adalah kepatuhan pasien dalam penatalaksanaan penyakit serta pendidikan kesehatan yang diterima pasien CKD.

Kepatuhan pasien dalam penatalaksanaan penyakitnya seperti terapi fisik pada penyakit dasarnya dan terapi nutrisi (pembatasan asupan cairan, kalium, fosfor). Kepatuhan pasien dalam hal ini dapat mempengaruhi proses mempertahankan kualitas hidup pasien itu sendiri. Pasien yang tidak patuh dalam penatalaksanaan penyakit dapat mempengaruhi keadaan umum pasien sehingga pasien menjadi lemah, kualitas hidup pasien menjadi kurang baik, yang dibuktikan dari adanya berbagai keluhan tersebut seperti sesak napas, edema pada sebagian tubuh, ekstremitas atau seluruh tubuh, seringnya mondok atau rawat inap karena terjadi keluhan tersebut hingga mungkin mendapatkan pengobatan atau terapi hemodialisis sebelum jadwal yang ditetapkan. peningkatan kepatuhan pasien dapat dilakukan melalui upaya pendidikan kesehatan.
Nursalam (2008) mengatakan bahwa pendidikan kesehatan adalah proses yang direncanakan dengan sadar untuk menciptakan peluang bagi individu - individu untuk senantiasa belajar memperbaiki kesadaran serta meningkatkan pengetahuan dan keterampilan demi kepentingan kesehatan. Pendidikan kesehatan ini merupakan perlakuan yang diberikan untuk mempengaruhi perubahan kepatuhan pasien dalam penatalaksanaan penyakitnya.

Berdasarkan survei awal yang dilakukan terdapat 40 pasien CKD yang mendapatkan terapi hemodialisis di rumah sakit Ichsan Medikal Center Bintaro Tangerang Selatan, dengan frekuensi $2 x$ dalam semiggu dan $3 x$ dalam seminggu. Penyebab dari kebanyakan pasien CKD yang di hemodialisis adalah diabetes mellitus dan hipertensi sehingga pasien harus dilakukan terapi hemodialisis. Penelitian ini bertujuan untuk mengetahui pengaruh pendidikan kesehatan yang diberikan pada pasien CKD yang menjalani hemodialisa (HD) terhadap kepatuhan pembatasan asupan cairan.

\section{Metodologi Penelitian}

Penelitian ini menggunakan desain penelitian quasi eksperimen dengan pendekatan pretest and post test nonequivalent control group design untuk mengetahui pengaruh pendidikan kesehatan yang diberikan pada pasien CKD yang menjalani hemodialisa (HD) terhadap kepatuhan pembatasan asupan cairan. Penelitian ini dilaksanakan di Unit Hemodialisis, Rumah Sakit IMC Bintaro Tangerang Selatan. Waktu penelitian dilaksanakan pada bulan Desember 2018 sampai dengan bulan Februari 2019. Populasi penelitian ini adalah seluruh pasien yang menjalani HD di Unit Hemodialisis Rumah Sakit IMC Bintaro Tangerang Selatan berjumlah 40 orang dengan sampel 40 orang yang termasuk dalam kriteria inklusi. Untuk kelompok eksperimen yaitu responden yang menjalani HD tiga kali seminggu sebanyak 20 orang dan kelompok kontrol yaitu responden yang menjalani HD dua kali seminggu sebanyak 20 orang yang dipilih dengan cara Purposive Sampling.

Instrumen yang digunakan dalam penelitian ini yaitu kuesioner (kuisioner data demografi dan kuisioner kepatuhan pembatasan cairan). Penelitian ini menggunakan kuisioner yang sudah ada yaitu kuisioner mengenai pembatasan asupan 
cairan dengan 20 pertanyaan, dengan menggunakan skala gutman. Analisis data menggunaan analisa univariate dan bivariate dengan pendekatan uji paired sample $t$ test dan independent $T$ test.

\section{Hasil dan Pembahasan}

Tabel 1: Gambaran Karakteristik Umum Responden /Pasien HD

\begin{tabular}{lcccc}
\hline \multirow{2}{*}{ Karaktersitik } & \multicolumn{2}{c}{$\begin{array}{c}\text { Kelompok } \\
\text { Kontrol }\end{array}$} & \multicolumn{2}{c}{ Kelompok } \\
& F & \% & F & \% \\
\cline { 2 - 5 } Usia & & & & \\
$\quad \begin{array}{l}\text { Dewasa muda } \\
\text { (18-40 tahun) }\end{array}$ & 5 & 25 & 2 & 10 \\
$\begin{array}{l}\text { Dewasa tengah } \\
\text { (41- 60 tahun) }\end{array}$ & 10 & 50 & 14 & 70 \\
Dewasa akhir & 2 & 25 & 4 & 20 \\
$\quad>60$ tahun) & & & & \\
\hline Jenis Kelamin & & & & \\
$\quad$ Laki-laki & 11 & 55 & 12 & 60 \\
$\quad$ Perempuan & 9 & 45 & 8 & 40 \\
\hline Tingkat & & & & \\
Pendidikan & & & & \\
$\quad$ SD & 2 & 10 & 4 & 20 \\
SMP & 0 & 0 & 2 & 10 \\
SMA & 15 & 75 & 7 & 35 \\
PT & 3 & 15 & 7 & 35 \\
\hline Status & & & & \\
Pekerjaan & & & & \\
Tidak Bekerja & 18 & 90 & 14 & 70 \\
Bekerja & 2 & 10 & 6 & 30 \\
\hline
\end{tabular}

Tabel 2: Gambaran Kepatuhan Responden

Kepatuhan pembatasan cairan responden pada kelompok kontrol dan eksperimen sebelum pendidikan kesehatan $(n=40)$

\begin{tabular}{lcccc}
\hline \multirow{2}{*}{$\begin{array}{c}\text { Tingkat } \\
\text { Kepatuhan }\end{array}$} & \multicolumn{2}{c}{$\begin{array}{c}\text { Kelompok } \\
\text { Kontrol }\end{array}$} & \multicolumn{2}{c}{$\begin{array}{c}\text { Kelompok } \\
\text { Eksperimen }\end{array}$} \\
\cline { 2 - 5 } & F & \% & F & \% \\
\hline Tidak Patuh & 11 & 55 & 12 & 60 \\
\hline Patuh & 9 & 45 & 8 & 40 \\
\hline Total & 20 & 100 & 20 & 100 \\
\hline
\end{tabular}

Tabel 3: Gambaran Kepatuhan Pembatasan Cairan Responden pada Kelompok Kontrol Setelah Pendidikan Kesehatan dan Kelompok Eksperimen tanpa Pendidikan Kesehatan

\begin{tabular}{|c|c|c|c|c|}
\hline \multirow{3}{*}{$\begin{array}{l}\text { Tingkat } \\
\text { Kepatuhan }\end{array}$} & \multirow{2}{*}{\multicolumn{2}{|c|}{$\begin{array}{c}\text { Sebelum } \\
\text { Pendidikan } \\
\text { Kesehatan } \\
\text { Kelompok } \\
\text { Kontrol }\end{array}$}} & \multirow{2}{*}{\multicolumn{2}{|c|}{$\begin{array}{c}\text { Setelah } \\
\text { Pendidikan } \\
\text { Kesehatan } \\
\text { Kolompok } \\
\text { Eksperimen }\end{array}$}} \\
\hline & & & & \\
\hline & $\mathbf{F}$ & $\%$ & $\mathbf{F}$ & $\%$ \\
\hline Tidak Patuh & 8 & 40 & 2 & 10 \\
\hline Patuh & 12 & 60 & 18 & 90 \\
\hline Total & 20 & 100 & 20 & 100 \\
\hline
\end{tabular}

Tabel 4: Perbedaan Tingkat Kepatuhan Pembatasan Cairan pada Kelompok Eksperimen $(n=40)$

\begin{tabular}{lccc}
\hline Variabel & $\begin{array}{c}\text { Sebelum } \\
\text { Penkes }\end{array}$ & $\begin{array}{c}\text { Setelah } \\
\text { Penkes }\end{array}$ & P Value \\
\cline { 1 - 3 } Tidak Patuh & 12 & 2 & \multirow{2}{*}{0,000} \\
\hline Patuh & 8 & 18 & \\
\hline
\end{tabular}

Tabel 5: Perbedaan Tingkat Kepatuhan Pembatasan Cairan pada Kelompok Kontrol $(\mathrm{n}=40)$

\begin{tabular}{lccc}
\hline Variabel & $\begin{array}{c}\text { Sebelum } \\
\text { Penkes }\end{array}$ & $\begin{array}{c}\text { Setelah } \\
\text { Penkes }\end{array}$ & P Value \\
\cline { 1 - 3 } Tidak Patuh & 11 & 8 & \multirow{2}{*}{0,330} \\
\cline { 1 - 3 } Patuh & 9 & 12 & \\
\hline
\end{tabular}

Tabel 6: Pengaruh Pendidikan Kesehatan terhadap Kepatuhan

\begin{tabular}{lccc}
\hline Variabel & $\begin{array}{c}\text { Sebelum } \\
\text { Penkes }\end{array}$ & $\begin{array}{c}\text { Setelah } \\
\text { Penkes }\end{array}$ & P Value \\
\cline { 1 - 3 } Tidak Patuh & 8 & 2 & \multirow{2}{*}{0,030} \\
\hline Patuh & 12 & 18 & \\
\hline
\end{tabular}

\section{Karakteristik Responden}

Berdasarkan hasil penelitian, umur yang paling banyak pada kelompok kontrol adalah berusia 41 - 60 tahun sebanyak 10 orang $(50 \%)$ dan kelompok eksperimen adalah berusia $41-60$ tahun sebanyak 14 orang (70\%). Gambaran usia diatas menunjukkan bahwa mayoritas pasien berada pada kelompok dewasa tengah $(41-60$ tahun). Usia berkaitan erat dengan tingkat kedewasaan atau maturitas, semakin meningkat usia maka semakin meningkat juga kedewasaan atau kematangan.

Berdasarkan hasil penelitian, terlihat bahwa karakteristik responden berdasarkan jenis kelamin, mayoritas adalah laki - laki pada kelompok kontrol sebanyak $55 \%$ dan kelompok eksperimen sebanyak $60 \%$. Hasil penelitian ini sejalan dengan penelitian yang dilakukan oleh (Sumigar \& 
Faletehan Health Journal, 8 (2) (2021) 140-146

www. journal.Ippm-stikesfa.ac.id/ojs/index.php/FHJ

ISSN 2088-673X | 2597-8667

Rompas, 2015) dengan judul hubungan dukungan keluarga dengan kepatuhan diet pada pasien ESRD. Penelitian lain yaitu Istanti (2014) menyatakan bahwa laki-laki cenderung lebih rentan terkena ESRD dikarenakan pekerjaan lakilaki lebih berat dari perempuan dan laki-laki terlalu sering mengkonsumsi suplemen. Menurut peneliti responden dengan jenis kelamin laki - laki banyak mempunyai presentasi yang besar dibandingkan perempuan karena gaya hidup laki - laki seperti kebiasaan yang dapat mempengaruhi kesehatan seperti merokok, minum kopi, alkohol, dan minum suplemen yang dapat memicu terjadinya penyakit sistemik yang dapat menurunkan fungsi ginjal.

Berdasarkan hasil penelitian, terlihat bahwa mayoritas responden pada kelompok kontrol adalah SMA sebanyak (75\%) sedangkan responden kelompok eksperimen adalah SMA sebanyak (35\%) dan perguruan tinggi sebanyak (35\%). Tingkat pendidikan merupakan indikator bahwa seseorang telah menempuh jenjang pendidikan formal tertentu. Pendidikan merupakan faktor yang penting dalam kehidupan sehari - hari. Tingkat pendidikan yang baik dapat mempengaruhi tingkat pengetahuan masyarakat dalam memahami informasi (Potter \& Perry, 2009).

Berdasarkan hasil penelitian, menunjukan bahwa status pekerjaan responden yang paling banyak pada kelompok kontrol adalah tidak bekerja sebanyak 18 orang $(90,0 \%)$ dan kelompok eksperimen adalah tidak bekerja sebanyak 14 orang (70\%).

\section{Kepatuhan Pembatasan Cairan pada Kelompok Control}

Kepatuhan pada kelompok kontrol sebelum pendidikan kesehatan yang paling banyak adalah tidak patuh sebanyak 11 orang (55\%). Kepatuhan (adherence) secara umum didefinisikan sebagai tingkatan perilaku seseorang yang mendapatkan pengobatan, mengikuti diet, dan melaksanakan gaya hidup sesuai dengan rekomendasi pemberi pelayanan kesehatan (Syamsiah, 2011). Kepatuhan dalam penelitian ini merupakan perilaku pasien hemodialisis terhadap instruksi atau perintah yang diberikan dalam upaya terapi yang telah ditetapkan yaitu pembatasan cairan selama menjalani HD.

Kepatuhan dalam menjalani HD dan pembatasan cairan sangat penting agar pasien merasa nyaman pada saat sebelum, selama dan setelah terapi HD (Imelda, 2012). Kepatuhan pembatasan cairan pada pasien CKD yang menjalani HD merupakan hal yang sangat penting untuk dilakukan, jika pasien tidak patuh akan terjadi penumpukan zat-zat berbahaya dalam tubuh. Salah satu faktor yang memiliki peran dalam membentuk kepatuhan pasien CKD yang menjalani HD yaitu pendidikan sehingga pasien mampu mengatur dirinya sendiri asupan makan dan minum (Liu \& Chertow, 2010).

\section{Kepatuhan Pembatasan Cairan pada Kelompok Eksperimen Sebelum Diberikan Pendidikan Kesehatan}

Kepatuhan pada kelompok eksperimen adalah tidak patuh sebanyak 12 orang $(60 \%)$. Kepatuhan pasien dalam mengurangi asupan cairan dirasakan masiih kurang dan merupakan prioritas utama diagnosa keperawatan yang ditegakan dalam memberikan pelayanan keperawatan pasien CKD yang menjalani HD rutin di RSUD Soehadi Prijonegoro Sragen tidak patuh sebanyak 11 orang (55 \%) dalam mengurangi asupan cairan (Hartati, 2016).

Hasil penelitian menunjukkan pada 12 pasien kelompok eksperimen yang menjalani HD tiga kali seminggu dengan lama HD 4 jam mengalami ascites, oedema ekstremitas dan tidak bisa buang air kecil lagi. Pasien belum merasakan ketidaknyamanan akibat kelebihan cairan sehingga cenderung tidak patuh. Temuan tersebut memerlukan mengoptimalkan peran dan fungsi perawat sebagai communicator, teacher, conselor, advocate dan leader untuk mencegah, meminimalisir dan mengatasi masalah kepatuhan melaluia pemberian asuhan keperawatan yang holistik sesuai dengan karakteristik pasien (Bangun, 2009).

\section{Kepatuhan Pembatasan Cairan pada Kelompok Kontrol tanpa Intervensi/ Pendidikan Kesehatan}

Pada kelompok kontrol menunjukkan responden dengan tingkat kepatuhan sebanyak $75 \%$, hal ini sejalan dengan penelitian Hartati (2016) yang menyebutkan bahwa kelompok kontrol patuh dalam pembatasan asupan cairan. Faktor yang dapat mempengaruhi perilaku adalah pengalaman pribadi, pengaruh orang lain yang dianggap penting, pengaruh kebudayaan, agama, faktor emosional serta pendidikan formal dan informal (Azwar, 2011). Efek yang akan timbul 
pada pasien CKD yang mengalami kelebihan cairan mengalami rasa tidak nyaman karena sesak nafas, lelah dan lemas. Hal tersebut mendorong pasien untuk mematuhi pembatasan asupan cairan.

\section{Kepatuhan Pembatasan Cairan pada Kelompok Eksperimen Sesudah Pendidikan Kesehatan}

Kepatuhan pada kelompok eksperimen setelah pendidikan kesehatan yang paling banyak adalah patuh sebanyak 18 orang (90 \%). Pendidikan kesehatan diartikan sebagai suatu proses yang terdiri dari pengkajian, intervensi dan evaluasi (Edelman \& Mandle, 2010). Pengkajian berguna menentukan kebutuhan, motivasi dan tujuan pembelajaran yang dibuat bersama pasien. Intervensi dilakukan untuk menyediakan sumber pembelajaran sesuai kebutuhan pasien dan evaluasi dilakukan selama proses pembelajaran maupun setiap tahap belajar untuk mengetahui pencapaian kemampuan. Media pembelajaran merupakan alat yang digunakan dalam pemberian informasi kesehatan. (Notoatmodjo, 2009) menyatakan media pendidikan adalah alat yang digunakan untuk membantu dalam menyampaikan bahan pendidikan atau pengajaran. Melalui media pembelajaran diharapkan pesan-pesan kesehatan dapat diterima dengan baik oleh responden sehingga mampu meningkatkan pengetahuan.

Pengetahuan yang dimiliki responden sebelumnya ditambah dengan informasi yang diberikan dapat meningkatkan pengetahuan menjadi lebih baik. Selain itu materi informasi juga merupakan hal yang menarik bagi responden karena berkaitan dengan upaya yang harus dilakukan pasien CKD yang menjalani HD dapat merasa nyaman sebelum, selama dan sesudah HD.

\section{Perbedaan Tingkat Kepatuhan Pembatasan Cairan pada Kelompok Eksperimen}

Hasil tingkat kepatuhan pada kelompok eksperimen sebelum dan sesudah pendidikan kesehatan ditemukan bahwa ada perbedaan kepatuhan pembatasan cairan pasien hemodialisis pada kelompok eksperimen. Tidak ada intervensi standar yang dapat meningkatkan kepatuhan, karena ada banyak hal yang berperan mempengaruhi kepatuhan. Ketidakpatuhan adalah individu tidak melaksanakan sebuah program pengobatan yang disarankan. Ketidakpatuhan dapat mendatangkan beberapa konsekuensi yang harus ditanggung individu. Beberapa konsekuensi mungkin tidak dirasakan secara langsung, namun dampak serius akibat sikap tidak patuh mampu memberikan efek dikemudian waktu (Saifunurmazah, 2013).

Pendapat peneliti terkait pengaruh intervensi terhadap kepatuhan pembatasan cairan responden terjadi karena informasi yang diberikan merupakan informasi yang secara umum sudah diketahui kebenarannya. Pasien CKD mengetahui bahwa pembatasan cairan diperlukan agar tidak mengalami komplikasi yang dapat menimbulkan ketidaknyamanan bahkan kematian. Kebenaran informasi menimbulkan keiginan untuk menerima informasi yang diberikan.

\section{Perbedaan Tingkat Kepatuhan Pembatasan Cairan pada Kelompok Kontrol}

Hasil tingkat kepatuhan pada kelompok kontrol sebelum pendidikan kesehatan dan tanpa pendidikan kesehatan ditemukan bahwa tidak ada perbedaan kepatuhan pembatasan cairan pasien hemodialisis pada kelompok kontrol.

Kepatuhan pembatasan asupan cairan tidak hanya berkaitan dengan pengetahuan dan sikap. Terdapat faktor lain baik internal maupun eksternal. Pembatasan cairan pada pasien hemodialisis sangat dipengaruhi oleh perubahan musim dan masa - masa tertentu seperti musim panas cairan pasien sangat tidak terkontrol, liburan, lebaran, natal dan tahun baru banyak mengkonsumsi makanan ringan dan mengandung garam sehingga mamacu keinginan untuk minum.

Kelompok kontrol tidak mengalami perubahan tingkat kepatuhan yang bermakna karena tidak mendapat pendidikan kesehatan. Pengetahuan kelompok kontrol tentang pembatasan asupan cairan hanya didapatkan dari informasi petugas kesehatan atau perawat pada awal pasien akan menjalani HD. Pemberian informasi yang minimal menyebabkan pemahaman pasien CKD tentang penyakit, terapi, pembatasan asupan cairan, perawatan dirumah dan komplikasi yang tidak optimal.

Faktor lain yang dapat mempengaruhi kepatuhan pasien adalah keterlibatan petugas kesehatan, waktu yang didedikasikan perawat untuk konseling pasien dapat meningkatkan kepatuhan pasien. Informasi tertentu dapat mempengaruhi perilaku sangat tergantung dari isi, sumber dan media informasi yang bersangkutan. Dilihat dari segi informasi adalah pesan yang disampaikan dalam proses komunikasi haruslah 
Faletehan Health Journal, 8 (2) (2021) 140-146

www. journal.Ippm-stikesfa.ac.id/ojs/index.php/FHJ

ISSN 2088-673X | 2597-8667

memiliki kemampuan untuk mempengaruhi keyakinan sasaran didik (Simamora, 2009).

\section{Pengaruh Pendidikan Kesehatan terhadap Kepatuhan}

Pendidikan kesehatan secara umum dapat diartikan sebagai upaya mengajak/mempengaruhi orang lain agar berperilaku hidup sehat. Melalui pendidikan kesehatan diharapkan terjadi perubahan pengetahuan, sikap dan perilaku kelompok sasaran. Pendidikan kesehatan dapat dilakukan dengan berbagai media, baik media cetak dan elektronik. Penggunaan leaflet, poster dan media non cetak seperti electronic power point dan film sebagai media promosi yang dapat digunakan untuk meningkatkan pengetahuan dan sikap responden (Pertiwi \& Annissa, 2019). Beberapa penelitian menunjukkan bahwa kelompok sasaran yang terpapar pendidikan kesehatan secara signifikan terjadi peningkatan pengetahuan dan sebanyak $97 \%$ responden menyatakan terpapar media promosi kesehatan (Kusuma, Pertiwi, Annissa, 2019). Pendidikan kesehatan dapat dilakukan dengan berbagai media baik cetak maupun non cetak (elektronik). Bentuk media cetak yang dapat digunakan dalam pendidikan kesehatan diantaranya adalah leaflet, brosur, poster dan lain-lain. Media elektronik dalam pendidikan kesehatan dapat berupa pemutaran film, radio, maupun menggunakan video. Pada penelitian ini, media yang digunakan adalah leaflet yang disampaikan dengan metode tanya jawab.

Pendidikan kesehatan tentang pembatasan asupan cairan merupakan suatu upaya memberikan informasi kepada pasien CKD yang menjalani hemodialisis di RS IMC Bintaro. Materi yang disampaikan tentang masalah kelebihan cairan, batasan asupan cairan, cara menghitung kebutuhan cairan dan tips membatasi asupan cairan pada pasien hemodialisis. Hasil tingkat kepatuhan pada kelompok kontrol dan eksperimen sesudah pendidikan kesehatan bahwa ada pengaruh pendidikan kesehatan terhadap tingkat kepatuhan. Hasil penelitian ini sejalan dengan penelitian yang dilakukan pada penelitian sebelumnya oleh Desak Putu (2015) yang menyatakan bahwa pendidikan kesehatan mengenai kepatuhan dapat terjadi karena kesiapan responden untuk belajar dan menghindari untuk masuk rawat inap atau hemodialisis sebelum jadwal yang ditentukan. Selama pendidikan kesehatan berlangsung responden menyimak dengan seksama yang dijelaskan. Antusias juga terlihat ketika ada hal yang kurang dipahami langsung ditanyakan.

\section{Simpulan}

Pendidikan kesehatan yang telah diberikan kepada pasien hemodialisis dengan menggunakan metode tanya jawab dan memberikan media leaflet mempunyai pengaruh terhadap kepatuhan pembatasan asupan cairan pasien hemodialisis. Pendidikan kesehatan yang diberikan pada kelompok intervensi berpengaruh terhadap kepatuhan pasien CKD dalam pembatasan asupan cairan dibandingkan dengan kelompok kontrol.

\section{Referensi}

Andiko Nugraha Kusuma, Wiwik Eko Pertiwi, Annissa. (2019). Healthy Media Promotion, Knowledge Towards Clean and Healthy Life Behavior among Students. Jurnal Fakultas Kesehatan Masyarakat Volume 13 (2), September 2019, pp. 70 75

Azwar, S. (2011). Sikap Dan Perilaku Dalam: Sikap Manusia Teori Dan Pengukuran. Yogyakarta: Pustaka Belajar.

Bangun, A. . (2009). Faktor-Faktor Yang Berkontribusi Terhadap Kepatuhan Pasien Tipe 2 Dalam Konteks Asuhan Keperawatan Di Ploklinik Endokrin RSHS Bandung. Universitas Indonesia.

Black, J. ., \& Hawks, J. . (2014). Keperawatan Medikal Bedah: Manajemen Klinis Untuk Hasil Yang Diharapkan (Edisi 8). Jakarta: Salemba Medika.

Bomback, \& Bakris. (2011). Chronic Kidney Disease (Jones \& Ba). Physycians Press.

Corwin. (2009). Buku Saku Patofisiologi (Edisi 3). Jakarta: EGC.

Desak Putu Kurniawati. (2015). Pengaruh Edukasi Terhadap Kepatuhan Intake Cairan Pasien PGK on HD. Skripsi. Universitas Airlangga

Edelman, \& Mandle. (2010). Health Promotion Through The Life Span. Canada: Mosby Elsevier.

Hartati, S. (2016). Pengaruh Pendidikan Kesehatan Asupan Cairan Dengan Media Audiovisual Terhadap Kepatuhan Pembatasan Cairan Pada Pasien Hemodialisa Di Ruang Hemodialisa RSUD $D R$. Soehadi Prijonegoro Sragen. STIKES KUSUMA HUSADA. 
Imelda. (2012). Analisis Faktor-Faktor Yang Mempengaruhi Kepatuhan Pembatasan Asupan Cairan Pada Klien Dengan Chronic Kidney Disease Yang Menjalani Hemodialisis. STIKes Telogorejo Semarang.

IRR (Indonesian Renal Registry). (2017).

Istanti, P.Y. (2014). Hubungan Antara Masukan Cairan Dengan Interdialytic Weight Gains (Idwg) Pada Klien Chronic Kidney Diseases Di Unit Hemodialisis Rs Pku Muhammadiyah Yogyakarta. PROFESI Volume 10 / September 2013 - Februari 2014

Liu, K. D., \& Chertow, G. M. (2010). Chapter 306: Dialysis In The Treatment Of Renal Failure.

Maryati. (2011). Hubungan Dukungan Keluarga Dengan Kepatuhan Diet Rendah Garam Pada Penderita Hipertensi Di Desa Bakarejo Wilayah Kerja Puskesmas Guntur Kabupaten Demak.

Notoatmodjo, S. (2009). Pengembangan Sumber Daya Manusia. Jakarta: PT Rineka Cipta.

Nursalam. (2008). Konsep dan Penerapan Metodologi Penelitian Ilmu Keperawatan. Jakarta: Salemba Medika.

Pertiwi, W. E., \& Annissa, A. (2019). the Evaluation of Health Promotion Media Availability in Elementary Schools. Jurnal PROMKES, 7(1), 100. https://doi.org/10.20473/jpk.v7.i1.2019.100104

Potter, \& Perry. (2009). Buku Ajar Fundamental Keperawatan (Edisi 4 Vo). Jakarta: EGC.

Saifunurmazah, D. (2013). Kepatuhan Diabetes Melitus Dalam Menjalani Terapi Olaraga Dan Diet. Universitas Negeri Semarang.

Simamora, R. . (2009). Dokumentasi Proses Keperawatan. Jember: Jember University Press.

Sumigar, G., \& Rompas, S. . (2015). Hubungan Dukungan Keluarga Dengan Kepatuhan Diet Pada Pasien GGK Di Irina C2 dan C4 RSUP Prof. DR. R. D. Kondou Manado. Jurnal Keperawatan, Vol 3.

Syamsiah, N. (2011). Faktor-Faktor Yang Berhubungan Dengan Kepatuhan Pasian CKD Yang Menjalani Hemodialisa di RSPAU DR Esnawan Antariksa Halim Perdana Kusuma Jakarta. 